\title{
O Campo da Pesquisa Qualitativa e o Método de Explicitação do Discurso Subjacente (MEDS)
}

\author{
The Field of Qualitative Research and the Underlying \\ Discourse Unveiling Method (UDUM)
}

\author{
Ana Maria Nicolaci-da-Costa* \\ Pontifícia Universidade Católica do Rio de Janeiro, Rio de Janeiro, Brasil
}

\begin{abstract}
Resumo
Desde o final do século XX, uma "revolução" qualitativa vem ocorrendo nas ciências sociais e humanas. Impelidos pela necessidade de explorar a fundo novos fenômenos humanos e sociais, inúmeros pesquisadores abandonaram o positivismo e abraçaram metodologias qualitativas. $\mathrm{O}$ campo da pesquisa qualitativa passou a abranger uma variedade tão grande de métodos que a discussão das especificidades de qualquer um deles requer a identificação dos pontos em que o método em questão se aproxima ou se distancia dos outros métodos que compõem o campo. Neste trabalho, tal procedimento é usado para a discussão das especificidades do Método de Explicitação do Discurso Subjacente (MEDS).
\end{abstract}

Palavras-chave: Métodos qualitativos; revolução qualitativa; MEDS; entrevistas; análise de discurso.

\begin{abstract}
Since the end of the 20th century, a qualitative "revolution" has been going on in the social and human sciences. Prompted by the need to attain deeper knowledge of new human and social phenomena, several researchers abandoned positivism and embraced qualitative methodologies. The field of qualitative research has become so vast that a discussion of the specificities of any particular method requires the identification of the similarities and differences that exist between such method and the various other methods in the field. In the present paper, this procedure is used for the discussion of the specificities of the Underlying Discourse Unveiling Method (UDUM).

Keywords: Qualitative methods; qualitative revolution; UDUM; interviews; discourse analysis.
\end{abstract}

\section{A “Revolução Qualitativa”}

Sabemos que o mundo mudou com o fim da Era moderna e a expansão das tecnologias digitais. Talvez em parte por conta da necessidade de explorar a fundo os diversos aspectos dessa mudança (Jodelet, 2003), o cenário das pesquisas nas ciências sociais e humanas também sofreu uma profunda transformação a partir do final do século XX: a chamada "revolução qualitativa" (Denzin \& Lincoln, 2000c).

Até então dominadas pelas metodologias quantitativas, essas ciências presenciaram uma difusão inédita e veloz das metodologias qualitativas inclusive em contextos tradicionalmente conhecidos por seu zelo quantitativo, como o norte-americano e o inglês. Alguns indicadores podem ajudar a avaliar a intensidade dessa transformação.

A mudança de rumo nas pesquisas sociais e humanas, por exemplo, é tornada visível pelas inúmeras publicações que se dedicam a um empreendimento antes raro principalmente no universo acadêmico anglo-saxão: realizar uma reflexão sobre os pressupostos, paradigmas, técnicas e características próprios da pesquisa qualitativa (Biasoli-Alves, 1998;

\footnotetext{
" Endereço para correspondência: Rua Marquês de São Vicente, 225, Gávea, Rio de Janeiro - RJ, 22543-900. Fone: (21) 3527-1183 / 3527-1185; Fax: (21) 35271187.E-mail:anicol@psi.puc-rio.br

Agradeço o apoio do $\mathrm{CNPq}$ e a leitura de uma versão prévia deste artigo feita por Carla Faria Leitão e Daniela Romão-Dias.
}

Brockmeier \& Harré, 2003; Denzin \& Lincoln, 2000b; Gomes, 1997; Jodelet, 2003; Lincoln \& Guba, 2000; Martins, 2004; Maxwell, 2005; Rubin \& Rubin, 2005; Taylor, 2001b; Turato, 2003; etc.). Tal reflexão, que muitas vezes recorre à pesquisa quantitativa como referência contrastiva, tem uma importante conseqüência: o delineamento de um "campo" autônomo da pesquisa qualitativa (Denzin \& Lincoln, 2000b) que torna desnecessário o contraponto qualitativo-quantitativo para descrever as metodologias qualitativas.

A velocidade da mudança, por seu turno, tem como um importante indicador a rapidez de reedição de inúmeras publicações. Chizotti (2000), por exemplo, teve seis edições publicadas entre 1991 e 2003; Denzin e Lincoln (2000a), três edições de um manual de cerca de 1000 páginas, entre 1994 e 2005; Maxwell (2005), duas edições, em 1996 e 2005; Rubin e Rubin (2005), duas edições, em 1995 e 2005; Seidman (1998), duas edições, em 1991 e 1998; Wengraf (2004), três edições em 2001, 2002 e 2004; Wetherell, Taylor e Yates (2001), duas edições, em 2001 e 2002.

Já a amplitude geográfica dessa difusão se torna nítida mediante a constatação de que as publicações sobre métodos qualitativos têm origem em contextos intelectuais tão diversos quanto o norte-americano, o inglês, o francês e o brasileiro, entre muitos outros. 
São, no entanto, as apresentações individuais de incontáveis métodos (para não falar de suas ainda mais numerosas aplicações) que dão à revolução qualitativa maior visibilidade e concretude. Denzin e Lincoln, que apresentam uma grande variedade desses métodos em sua volumosa coletânea, assinalam que "nunca houve tantos paradigmas, estratégias de investigação, ou métodos de análise dos quais o pesquisador possa lançar mão" (2000c, p. 18).

Entre todos esses métodos encontram-se aqueles que fazem uso de entrevistas para a coleta de dados (Gomes, 1997; Kvale, 1996; Maxwell, 2005; Rubin \& Rubin, 2005; Seidman, 1998; Taylor, 2001b; Turato, 2003; Weiss, 1994; Wengraf, 2004; etc.). Embora representem apenas um dos vários tipos possíveis de métodos qualitativos, os métodos baseados em entrevistas têm um importante aspecto em comum com todos os demais métodos que pertencem ao campo da pesquisa qualitativa: são adotados por pesquisadores que partilham a firme convicção de que a adequação de um método depende dos objetivos da pesquisa. Como os objetivos das pesquisas humanas e sociais são numerosos também são numerosos os métodos.

\section{Inserindo o Método de Explicitação do Discurso Subjacente (MEDS) no Campo da Pesquisa Qualitativa}

Em decorrência dessa profusão de métodos, a apresentação das características específicas de um método qualitativo particular, como a do Método de Explicitação do Discurso Subjacente (MEDS) que é o objetivo deste trabalho, torna-se uma tarefa pouco trivial. Pouco trivial porque, como qualquer outro método que se insira neste amplo e diversificado campo de possibilidades metodológicas, sua especificidade só poderá ser avaliada em função dos pontos em que se aproxima ou se distancia dos demais métodos que formam o campo. Ainda que sejam considerados somente os métodos qualitativos que, como o MEDS, usam entrevistas para a coleta de dados, esse campo é tão amplo que se torna impossível mapeá-lo a contento. Resta, portanto, a alternativa de contrastar o MEDS com métodos, estratégias e procedimentos eleitos como representativos da diversidade de opções metodológicas que compõem o campo como um todo. Isso será feito a seguir.

Para que pudesse ser obtido um espectro de contrastes que fizesse jus à diversidade dos métodos qualitativos que utilizam entrevistas, foram escolhidas propostas e/ ou princípios metodológicos que não somente revelam ter objetivos bastante divergentes, mas também são provenientes de seis áreas diferentes das ciências humanas e sociais: Educação (Seidman, 1998), Sociologia (Weiss, 1994), Antropologia e Educação Médica (Maxwell, 2005), Urbanismo e Administração Pública (Rubin \& Rubin, 2005), Psicanálise e Psiquiatria (Turato, 2003) e Psicologia Social (Taylor, 2001b). O campo de opções assim delineado servirá de referência e fornecerá os contrastes necessários para a apresentação das características do MEDS bem como para a identificação de suas especificidades.

\section{As Características e Especificidades do MEDS}

O MEDS é o resultado da recente integração de diferentes procedimentos metodológicos empregados ao longo de mais de duas décadas de prática de pesquisa em psicologia clínica. Embora tenha vários pontos em comum com outros métodos qualitativos que fazem uso de entrevistas, apresenta algumas importantes características singulares em virtude de seus objetivos e de suas origens interdisciplinares.

\section{Características Gerais}

O registro explícito do papel do discurso nas diferentes fases do método. Um dos principais aspectos distintivos do MEDS é o registro explícito que faz do papel que a linguagem em contex to - ou seja, o discurso - nele desempenha (Nicolacida-Costa, 1994). Embora todos os métodos selecionados trabalhem com material discursivo, um registro análogo é encontrado somente em Taylor (2001b). Todos os outros métodos escolhidos (Maxwell, 2005; Rubin \& Rubin, 2005; Seidman, 1998; Turato, 2003; Weiss, 1994) tratam a linguagem apenas como uma ferramenta e não lhe dispensam maior atenção.

O registro explícito que o MEDS faz de que trabalha com material discursivo tem várias conseqüências de ordem prática tanto para a coleta quanto para a análise dos dados. Todas serão discutidas em maior detalhe ao longo deste trabalho.

Pressupostos. Tanto no MEDS quanto nos princípios metodológicos apresentados por Taylor (2001b), o papel da linguagem transcende, contudo, essas conseqüências práticas. Em ambos atribui-se à língua em uso, concebida como expressão do todo social, o importante papel de construir a nossa percepção da realidade. Para Taylor (2001b), essa construção parece se restringir à realidade externa (ou seja, àquilo que podemos perceber do mundo e das pessoas que nos rodeiam). O MEDS, contudo, vai um passo além e, juntamente com outros autores (Bernstein, 1977; Foucault, 1966), parte do pressuposto de que, ao internalizarmos uma língua nos contex tos em que ela é naturalmente usada, internalizamos todo um conjunto de conceitos, regras, valores, etc. que caracterizam uma determinada sociedade ou grupo social em um determinado período. Esse processo de internalização, por seu turno, nos constitui como sujeitos individuais. Segue-se que, uma vez que o discurso nos constrói e reconstrói como sujeitos em conformidade com os valores sociais dos grupos aos quais pertencemos ao longo da vida (Bernstein, 1977; Foucault, 1966; Nicolaci-da-Costa, 1987), o discurso também pode revelar os valores a partir dos quais se dão essa construção e reconstrução.

Influências. Os pressupostos acima já revelam algumas das origens interdisciplinares do MEDS, cuja composição também é bastante singular. Além da já óbvia influência de teorias de linguagem (Sapir, 1949; Saussure, 1916/1974), da construção social da realidade (Berger \& Luckmann, 1967) e da construção social da subjetividade (Bernstein, 1977; Foucault, 1966), o MEDS incorpora alguns pressu- 
postos e técnicas de investigação clínica oriundos da psicanálise (Sauret, 2003).

Da lingüística, além do preceito de trabalhar com uma concepção explícita de linguagem, o MEDS absorveu várias diretrizes práticas. Uma delas é a de coletar discursos em contextos naturais e informais (Labov, 1972). Embora o MEDS partilhe esta diretriz com todos os outros métodos selecionados, nestes últimos ela pode ter origens diferentes (como, por exemplo, na etnografia). Outra diretriz que o MEDS absorveu da lingüística já não é tão freqüentemente adotada: a de ter cuidados especiais (ditados pelos objetivos da pesquisa) com as formas de transcrever o discurso coletado (ver seção sobre transcrição). Este tipo de preocupação o MEDS partilha com Taylor (2001b) e Rubin e Rubin (2005).

Das teorias da construção social da realidade e da subjetividade (Berger \& Luckmann, 1967; Bernstein, 1977; Foucault, 1966), o MEDS incorporou o pressuposto de que a forma de percebermos o mundo bem como os modos de pensarmos, agirmos e sentirmos são socialmente construídos, principalmente por meio da língua em uso (estando, portanto, sempre referidos a um contex to social específico).

Por último, embora não adotando uma perspectiva psicanalítica, o MEDS sofreu a influência de algumas contribuições da psicanálise (Sauret, 2003). Nela se inspirando, adotou a técnica clínica da livre escuta que, por não ser intrusiva, capta aquilo que é importante para o outro (técnicas análogas, embora nem sempre tendo origem na psicanálise, são adotadas por todos os métodos escolhidos). Diferentemente da maior parte dos métodos em questão (à exceção de Turato, 2003), o MEDS também incorporou o já mencionado pressuposto de que, se usadas técnicas adequadas, pode-se alcançar o significado (muitas vezes inconsciente) que subjaz o que dizemos. Inspirado no princípio da associação livre, o MEDS adotou, ainda, o pressuposto de que aquilo que é importante para alguém a respeito de um determinado tema ou assunto inevitavelmente aparece no seu discurso espontâneo sobre o mesmo.

Objetivos. O MEDS e todos os métodos qualitativos selecionados têm um mesmo objetivo genérico: o de ouvir detalhadamente (a profundidade é um alvo comum) aquilo que, em contextos naturais e da forma mais livre possível, os entrevistados têm a dizer.

Já os objetivos específicos variam muito. A apresentação de todos os métodos em discussão é ilustrada por pesquisas que os adotaram. Para que o leitor deste artigo possa ter contato com a diversidade de questões que abrangem, seguem-se alguns exemplos dos temas investigados nas pesquisas usadas como ilustração: a educação anti-racista (Seidman, 1998); a adaptação à aposentadoria (Weiss, 1994); os grupos de apoio para pacientes com câncer (Maxwell, 2005); as dificuldades enfrentadas pela população de baixa renda em determinados contextos urbanos (Rubin \& Rubin, 2005); o binômio saúde-doença (Turato, 2003); a construção da identidade (Taylor, 2001b). À exceção das pesquisas apresentadas por Turato (2003), todas as demais têm algo em comum: o objetivo conhecer as opiniões, as crenças, as experiências, os sentimentos, etc. conscientemente explicitados pelos entrevistados em seus depoimentos.

O MEDS tem um objetivo distinto. De modo a subsidiar a pesquisa em psicologia clínica, foi desenvolvido com o principal intuito de trazer à tona transformações e conflitos psicológicos que muitas vezes não são verbalizados explicitamente pelos entrevistados porque deles eles próprios não têm consciência. Suas ainda incompletas versões anteriores, por conseqüência, têm sido freqüentemente empregadas para investigar as transformações e os conflitos de cunho psicológico resultantes de mudanças sociais geradas por fatores econômicos, políticos, tecnológicos, etc. (Nicolaci-da-Costa, 1987, 1998).

\section{As Diferentes Fases do MEDS na Execução de uma Pesquisa}

O MEDS tem muito em comum com os métodos qualitativos selecionados. Guarda, no entanto, importantes diferenças em relação à maior parte deles. Uma delas diz respeito ao fato de que o MEDS partilha somente com Seidman (1998) a característica de ter uma seqüência de fases bem delimitada. Cada uma dessas fases, que têm características singulares nesses dois métodos, será discutida a seguir no que diz respeito ao MEDS.

\section{Fase 1: Seleção da Amostra}

Recrutamento dos participantes. Muitos acham que o conceito de amostra se aplica exclusivamente às pesquisas quantitativas. Todos os métodos qualitativos sob investigação, no entanto, transportam este conceito para o campo da pesquisa qualitativa. Este transporte obviamente requer adaptações (ver também a seção sobre generalização adiante). Dado que envolvem intenso trabalho artesanal (Rubin \& Rubin, 2005; Weiss, 1994), as pesquisas qualitativas demandam muita dedicação e tempo (Taylor, 2001b). Tal demanda, por seu turno, resulta no uso generalizado de amostras pequenas, cujo recrutamento, ao invés de randômico, é quase sempre intencional (Maxwell, 2005) e objeto de muita reflexão.

$\mathrm{Na}$ literatura selecionada, os procedimentos apresentados para realizar esse recrutamento são vários e seguem um de dois princípios básicos: a heterogeneidade ou a homogeneidade de características chave dos participantes.

Quando adotam o princípio da heterogeneidade, os pesquisadores (Maxwell, 2005; Rubin \& Rubin, 2005; Seidman, 1998; Weiss, 1994) afirmam visar a maximização do alcance da pesquisa na medida em que vários tipos de pessoas poderão com ela se identificar. Um dos melhores exemplos da aplicação desse princípio é o da estratégia de "variação máxima", que dita que os participantes devem ser propositalmente selecionados por apresentarem características diferentes naquelas dimensões que são importantes para a pesquisa (Maxwell, 2005; Weiss, 1994). Há ainda um outro procedimento que pode gerar amostras heterogêneas, sem que essa heterogeneidade seja controlada pelo pesquisador. Este procedimento é o da seleção tipo "bola de neve" (Seidman, 1998; Turato, 2003; Weiss, 1994), na qual um participante indica outros e assim por diante. 
A preocupação com a homogeneidade da amostra, em contrapartida, se manifesta por meio do recrutamento dos participantes a partir de critérios pré-estabelecidos em função dos objetivos da pesquisa (Maxwell, 2005; Turato, 2003). Segundo Turato, estes critérios podem almejar simplesmente uma homogeneidade fundamental (como, por exemplo, uma patologia ou uma característica importante em comum) ou uma homogeneidade ampla (como, por exemplo, vários atributos pessoais - idade, sexo, ocupação, classe social, etc. - em comum além da referida patologia ou característica).

Embora o MEDS não adote uma única forma de recrutamento, sempre busca a homogeneidade (fundamental ou ampla) a partir de critérios pré-estabelecidos. Na realidade, freqüentemente privilegia um tipo de recrutamento que possibilita o enquadramento dos participantes naquele que é denominado "perfil de alta definição", uma versão rigorosa da homogeneidade ampla mencionada por Turato (2003).

Este perfil pode ser construído a partir de tantos critérios quantos sejam necessários para identificar os membros de um grupo social específico. Esta identificação é importante porque, como já dito, um dos principais objetivos do MEDS é a investigação dos conflitos e/ ou transformações internas gerados por situações novas (como, por exemplo, a incorporação ao cotidiano de novas tecnologias de telecomunicação como os celulares; Nicolaci-da-Costa, 2004) e/ ou situações críticas (como, por exemplo, a do descasamento; Nicolacida-Costa, 1987) que muitas vezes ocorrem com maior incidência em grupos sociais particulares em uma determinada época. De modo a oferecer uma ilustração mais precisa, no caso da pesquisa sobre o uso dos celulares (Nicolaci-da-Costa, 2004), este perfil de alta definição foi obtido a partir dos seguintes critérios: os participantes deveriam ter entre $18 \mathrm{e}$ 25 anos, ser universitários, solteiros, residentes da zona sul da cidade do Rio de Janeiro, morar com a família e ter celular próprio há mais de dois anos.

Decisões a respeito do tamanho da amostra. Apesar de todas as diferenças entre os diversos métodos que vêm sendo discutidos, a adequação do emprego de amostras pequenas nas pesquisas qualitativas é consensual. Números de participantes são raramente estipulados a priori na medida em que o principal critério usado para determinar se as entrevistas realizadas são suficientes para a investigação de um determinado assunto é o da saturação da informação. Por saturação da informação entende-se o fenômeno que ocorre quando, após um certo número de entrevistas, o entrevistador começa a ouvir, de novos entrevistados, relatos muito semelhantes àqueles que já ouviu, havendo uma rarefação de informações novas.

Seidman (1998) e Turato (2003) oferecem boas discussões deste momento, conhecido como "ponto de saturação" (Bertaux, 1981, citado por Seidman 1998). Seidman relata que alguns pesquisadores chegam a tentar identificar quando isso acontece em suas pesquisas. Douglas (1985, citado por Seidman, 1998), por exemplo, afirma que sua amostra ideal teria 25 participantes. $\mathrm{O}$ mesmo fenômeno acontece nas pesquisas realizadas com o MEDS e nossa experiência, que não é muito diferente da de Douglas, dita que 20 participantes constituem um bom número alvo (sendo que muitas vezes um número menor é suficiente).

\section{Fase 2: A Construção do Roteiro para as Entrevistas}

Antes de dar início à coleta de dados, é necessária a construção do instrumento que servirá de base a essa coleta. Todos os métodos sob discussão fazem uso de algum guia ou roteiro de tópicos, mas estes raramente têm sua construção descrita em detalhes.

Já o MEDS é detalhista, pois adota o ponto de vista de que um bom roteiro é indispensável para uma boa pesquisa. Por esse motivo, estipula diretrizes gerais para a construção de roteiros. As principais são: (a) os roteiros do MEDS devem ser estruturados em sua concepção (porém flexíveis em sua aplicação, como será discutido na próxima seção); (b) tendo em vista o registro explícito que o MEDS faz do fato de que trabalha com a língua em uso, esses roteiros devem se inspirar em conversas naturais (para isso, são usadas as entrevistas-piloto); (c) para evitar que as perguntas sejam lidas (e, conseqüentemente, soem artificiais para os entrevistados), os roteiros devem constar apenas de itens a partir dos quais serão geradas as perguntas durante as próprias entrevistas; (d) para que o entrevistador possa conhecer o ponto de vista do entrevistado, os itens devem gerar perguntas abertas que comportem qualquer tipo de resposta (como, por exemplo, "O que você acha de $\mathrm{x}$ ?", "O que y gera em você?). Perguntas de esclarecimento e/ ou aprofundamento (como "por quê?", "como?", "dá para explicar melhor?”, etc.) também devem ser previstas (mas podem ser introduzidas a qualquer momento em que sejam consideradas necessárias); (e) para preservar a naturalidade de uma conversa informal (que nunca é composta somente de perguntas abertas), alguns itens deverão gerar perguntas fechadas (cujas respostas são sim ou não, como, por exemplo, "Você gosta de z?"), seguidas de perguntas de esclarecimento e/ ou aprofundamento; (f) itens que geram perguntas mais abstratas - que solicitam opiniões, reflexões, posturas, sentimentos, avaliações, etc. do entrevistado - a respeito de determinados tópicos devem poder ser confrontados com itens que geram informações objetivas a respeito dos mesmos tópicos. Um bom exemplo do resultado deste confronto é o contraste entre a opinião que um jovem recém-casado revela ter sobre a divisão conjugal do trabalho doméstico (a de que tudo é feito equanimemente por ambos os membros do casal) e as informações concretas que ele próprio fornece sobre quem faz o quê dentro do casal: quem dirige, quem leva o carro para o conserto, quem cozinha, quem arruma a casa, quem vai ao supermercado, etc. (informações que podem revelar a existência de uma divisão de trabalho convencional). O raciocínio por trás deste procedimento é o de que o contraste entre informações concretas e afirmações abstratas (muitas vezes "politicamente corretas") tem o potencial de revelar as contradições existentes nos discursos dos entrevistados. Essas contradições, por sua vez, são importantes vias de acesso ao discurso subjacente (no caso citado, poderiam, por exemplo, revelar que, embora o 
discurso "explícito" do entrevistado seja o da igualdade de direitos, o que jaz por trás dele é a crença de que a divisão tradicional de papéis entre os membros do casal é "natural").

De acordo com essas diretrizes, portanto, a construção de um roteiro tem início em conversas informais, sem qualquer tipo de estrutura previamente delineado, sobre a temática a ser investigada. Para garantir que o roteiro seja adequado à população alvo, é importante que essas conversas iniciais ocorram com pessoas que apresentem um perfil análogo àquele delineado para os participantes da pesquisa. Um primeiro rascunho de roteiro deverá ser elaborado a partir dessas conversas. Esse rascunho, por sua vez, deverá ser testado em outras conversas, que, por já terem uma estrutura provisória, são chamadas de entrevistas-piloto. Muito provavelmente, a partir dessas entrevistas, o roteiro sofrerá sucessivas modificações e será submetido a novos testes. Quando tudo fluir bem (este é o melhor critério), o roteiro estará pronto.

Seguem, como exemplo, dois dos blocos temáticos nos quais foram agrupados os itens do roteiro utilizado em uma investigação dos impactos psicológicos dos telefones celulares. O contraste entre os itens que solicitam informações concretas no primeiro bloco e aqueles que solicitam as opiniões dos entrevistados no segundo de fato produziu inúmeras contradições, que podem ser inspecionadas em Nicolaci-da-Costa (2004).

1. Uso do celular: se o entrevistado tem o celular sempre por perto (onde?); qual a rotina de uso (investigar se recebe mais chamadas ou se faz mais chamadas); como se sente com a possibilidade de ser encontrado a qualquer hora; quanto tempo deixa o celular ligado por dia (quando deixa desligado; quando deixa na campainha, no vibracall ou no silencioso); se atende a qualquer hora (em caso negativo, quando não atende; quais os critérios que usa para atender ou não); se olha o visor antes de atender (em caso positivo, o que faz após olhar o visor); se há pessoas que o entrevistado sempre atende (em caso positivo, quem são e por quê sempre atende); se há alguém que o entrevistado nunca atende (em caso positivo, quem e por quê); se usa toque diferenciado (em caso positivo, para quem, por quê, quantos, etc.).

2. Privacidade e intimidade: o que é privacidade; como fica a privacidade com o uso do celular; o que é intimidade; como fica a intimidade com o uso do celular.

\section{Fase 3: As Entrevistas}

Aspectos gerais. No MEDS, tal como nos outros métodos que vêm sendo discutidos ao longo deste artigo, cada participante é entrevistado individualmente por um único entrevistador. Em todos os casos, as entrevistas acontecem em horários negociados entre entrevistadores e entrevistados. Como todas as entrevistas têm como modelo uma conversa informal, elas são sempre conduzidas em lugares com os quais os participantes se acham familiarizados e nos quais se sentem à vontade. No caso do MEDS, os entrevistados são, inclusive, solicitados a indicar os locais de sua preferência (restrições sendo colocadas somente aos locais muito ruidosos). Também em todos os casos estudados, antes da entrevista, os participantes devem assinar um termo de livre consentimento do qual constam informações sobre os objetivos da pesquisa, sobre os eventuais riscos que ela pode representar para aqueles que dela participam e sobre o uso que pode ser feito do material coletado.

No que diz respeito ao número de entrevistas a serem realizadas com cada participante, há muitas diferenças entre os métodos sob escrutínio. Alguns sugerem que sejam feitas duas (Weiss, 1994) ou três entrevistas com cada participante (Seidman, 1998). Na maioria das vezes, no entanto, é feita uma única entrevista com cada um deles. Este é o caso do MEDS. A duração das entrevistas também varia muito. As mais freqüentes são as entrevistas que duram entre uma e duas horas. As do MEDS geralmente não ultrapassam uma hora. Em todos os casos, as entrevistas são gravadas na íntegra (em áudio) com o consentimento dos entrevistados.

A realização das entrevistas. Em vários dos métodos selecionados, os pesquisadores evitam utilizar roteiros estruturados e padronizados porque acham que estes impedem o aprofundamento desejado, na medida em que supostamente geram perguntas feitas exatamente na ordem prevista sem que haja a possibilidade de qualquer intervenção espontânea por parte do entrevistador (Maxwell, 2005; Rubin \& Rubin, 2005; Turato, 2003; Weiss, 1994). Assim sendo, esses pesquisadores preferem adotar guias ou roteiros pouco estruturados e não padronizados, nos quais os entrevistadores têm liberdade para introduzir novas perguntas a cada entrevista. Esse procedimento tem, porém, uma séria conseqüência prática: inviabiliza análises comparativas, pois diferentes questões podem ser colocadas para diferentes entrevistados.

O MEDS, em contrapartida, estipula que o entrevistador deverá ter em mãos um roteiro estruturado que deverá ser aplicado de forma flexível para respeitar o fluxo de associações do entrevistado. Isso significa dizer que a ordem dos itens pode ser alterada; que, dependendo dos pronunciamentos dos entrevistados, alguns itens talvez sequer necessitem ser transformados em perguntas porque já foram por eles abordados espontaneamente; e que, apesar de todas essas alterações, o entrevistador deve estar atento para que nenhum dos itens do roteiro deixe de ser abordado. O MEDS incentiva a introdução espontânea somente de perguntas de aprofundamento ou esclarecimento.

Esta aplicação flexível de um roteiro estruturado tem os seguintes resultados práticos: (a) do ponto de vista do pesquisador, ela gera entrevistas semi-estruturadas comparáveis na medida em que, independentemente da ordem em que aparecem, os itens abordados são os mesmos para todos os participantes; (b) do ponto de vista dos participantes, essas entrevistas, se bem conduzidas, têm uma estrutura invisível porque se assemelham a uma conversa na qual podem se pronunciar sem restrições - e sem que o fluxo de suas associações seja interrompido - a respeito 
dos tópicos que lhes são apresentados; (c) do ponto de vista do entrevistador, a estrutura do roteiro transmite segurança, enquanto a flexibilidade de sua aplicação, a abertura de seus itens bem como a possibilidade de introdução de perguntas de esclarecimento lhe dão a possibilidade de aprofundar ou investigar melhor aquilo que achar necessário.

\section{Fase 4: A Transcrição dos Depoimentos}

A transcrição das entrevistas é tratada de forma genérica por praticamente todos os métodos escolhidos à exceção de Rubin e Rubin (2005) e, principalmente, Taylor (2001b). Estas duas propostas metodológicas têm em comum com o MEDS preocupações mais minuciosas como, por exemplo, aquelas com o nível de detalhamento necessário para os objetivos da pesquisa (muitos detalhes podem atrapalhar, mas certos detalhes - como hesitações e longas pausas em entrevistas que lidam com conflitos psicológicos, por exemplo - podem ser imprescindíveis). Embora as entrevistas geralmente sejam transcritas na íntegra, há quem sugira a transcrição somente dos trechos a serem citados (Weiss, 1994).

O MEDS aconselha que o nível de detalhamento das transcrições seja pensado e descrito caso a caso. Apesar de esta não ser uma preocupação explicitada na literatura consultada, o MEDS também enfatiza que as falas dos entrevistados não devem ser alteradas ou editadas. Erros gramaticais, palavrões, expressões chulas e congêneres devem ser transcritos, pois, quando presentes, fazem parte do discurso dos participantes.

\section{Fase 5: A Análise dos Depoimentos Coletados}

Considerações gerais. Todos os métodos selecionados para servir de contextualização ao MEDS e o próprio MEDS têm como objetivo a interpretação dos depoimentos coletados e não a verificação de hipóteses. Mesmo assim, essa interpretação pode ser realizada de dois modos diferentes: (a) a partir de categorias que emergem das falas dos entrevistados, o que caracteriza a abordagem êmica; e (b) a partir de categorias prévias oriundas das teorias que servem de base à pesquisa, o que caracteriza a abordagem ética (Taylor, 2001b; Turato, 2003). Embora algumas dos pesquisadores mencionados recorram à abordagem ética (Maxwell, 2005; Rubin \& Rubin, 2005; Weiss, 1994), todas as propostas selecionadas e também o MEDS privilegiam a abordagem êmica.

As propostas em discussão, porém, divergem bastante quanto ao início da análise do material coletado. Na maior parte delas, a análise tem início com a primeira entrevista e continua ao longo do processo de coleta de dados. Somente Seidman (1998) e o MEDS começam a analisar os depoimentos coletados depois de realizadas todas as entrevistas.

Outras diferenças, relativas aos tipos de análise levados a cabo, agrupam os métodos sob consideração de outra forma. O tipo de análise a ser realizado decorre dos pressupostos adotados e das decisões tomadas ao longo da pesquisa. Comparações sistemáticas entre as falas dos participantes, portanto, não podem ser feitas pelos métodos que não usam guias padronizados (a maioria dos que estão em discussão). Já o material coletado a partir de amostras heterogêneas deve receber tratamento especial porque parte da análise consiste em delinear os diferentes perfis dos respondentes (Seidman, 1998).

Apesar dessas diferenças, as análises realizadas por todos os métodos selecionados têm em comum o fato de procurar identificar regularidades, padrões e outros aspectos recorrentes nos depoimentos que analisam (tanto é que, na maior parte das vezes, a coleta de dados é considerada suficiente quando atinge o já discutido "ponto de saturação").

\section{A Análise Propriamente Dita}

Em praticamente todos os métodos que vimos discutindo, as entrevistas não recebem tratamento individualizado. Em geral, a análise do material é levada a cabo tendo por base comparações e outros procedimentos (como, por exemplo, o levantamento da incidência de um determinado conceito) realizados a partir dos depoimentos coletados pelas entrevistas como um todo. Dado que as entrevistas não podem ser comparadas item por item, são comparados conceitos e temas que nelas aparecem. São também combinados eventos separados para formular uma descrição integrada de um determinado fenômeno ou conjunto de fenômenos. Talvez por isso, Denzin e Lincoln (2000b) comparem o trabalho de análise qualitativa a uma bricolagem ou à confecção de uma colcha de retalhos.

O MEDS se diferencia muito dos outros métodos sob escrutínio porque, nele, o trabalho de análise dos depoimentos coletados tem duas etapas igualmente importantes: (a) a da análise das respostas dadas pelo grupo como um todo, chamada de análise inter-participantes; e (b) a análise detalhada de cada uma das entrevistas individuais, chamada de análise intra-participantes. Mesmo considerando somente a primeira, ou seja, a análise inter-participantes, o MEDS já se diferencia dos demais métodos em discussão. $O$ fato de que, nele, os participantes têm um perfil homogêneo e se pronunciam sobre todos os itens do roteiro permite que, diferentemente do que acontece em outros métodos, suas repostas sejam sistematicamente comparadas em busca de recorrências. Dessas recorrências, por sua vez, emergem categorias - sempre êmicas - que dão visibilidade aos valores do grupo social ao qual os entrevistados pertencem. A análise inter-participantes tem também o importante papel de fornecer ao pesquisador uma visão geral dos resultados obtidos, visão essa que será aprofundada na análise das entrevistas individuais.

O MEDS é o único dos métodos em discussão a realizar uma análise sistemática das respostas individuais, fazendo comparações internas aos depoimentos de cada um dos entrevistados. Estas comparações buscam inconsistências, contradições, novos conceitos, novos usos de linguagem, etc. no discurso de cada um dos participantes. Como não poderia deixar de ser, a especificidade da análise intra-participantes do MEDS é o resultado direto dos procedimentos por ele estipulados para a construção de roteiros e para a realização das entrevistas, todos eles discutidos anteriormente. 
Para fins de maior clareza, retomemos alguns desses procedimentos, começando pela realização das entrevistas.

Apesar de terem um roteiro estruturado como base, no MEDS, como já mencionado, as entrevistas são caracterizadas pela informalidade, pela descontração e pela liberdade que o entrevistado tem de associar livremente em resposta às questões que lhe são colocadas. Essa liberdade de expressão é fundamental para que emerja o desconhecido (aquilo que o pesquisador não pode prever e deseja conhecer). É também imprescindível para que uma das principais características do roteiro do MEDS - o contraste entre respostas abstratas e concretas - atinja seu objetivo de ganhar acesso ao discurso subjacente ao gerar contradições.

Como já foi visto, os roteiros do MEDS geralmente incluem itens que geram perguntas abstratas e itens que produzem informações objetivas sobre os mesmos tópicos. Quando comparadas, as respostas a esses dois tipos de pergunta podem não resultar em nenhuma inconsistência da parte do entrevistado. Quando da investigação dos impactos psicológicos decorrentes de processos de transformação social, no entanto, esses contrastes freqüentemente geram contradições que, associadas a outras características discursivas (como o uso de neologismos ou o emprego de termos antigos com novos significados), são as principais vias de acesso aos conflitos e transformações de cunho interno para a investigação dos quais o MEDS foi desenvolvido. Deles já foi dado um exemplo que vale ser retomado: o do jovem entrevistado que, embora afirmando que há igualdade na divisão conjugal do trabalho doméstico, entra em contradição consigo mesmo ao fornecer, como seus, os indicadores comportamentais de uma divisão de trabalho tradicional.

Ocorre que, em uma amostra homogênea, tudo que seja fruto de construção social tende a ser recorrente. Por esse motivo, qualquer aspecto que seja julgado importante na análise das respostas dadas por cada um dos participantes (contradições, neologismos, novas construções gramaticais, etc.) deve gerar categorias (obviamente êmicas) cuja presença nas entrevistas dos demais entrevistados deve ser investigada, o que levará o pesquisador de volta à análise inter-participantes. Para ilustrar esse procedimento, continuemos com o exemplo da contradição existente entre as opiniões (vanguardistas) que o já citado jovem entrevistado emite sobre a divisão do trabalho doméstico e as tarefas (tradicionais) que ele revela serem desempenhadas por si próprio e sua parceira. Caso essa contradição tenha suas raízes em algum processo de transformação social, como aquele que aconteceu no Brasil nas décadas de 1960 e 70 (Nicolaci-daCosta, 1987), é muito provável que a própria contradição seja recorrente no discurso dos entrevistados como um todo. O pesquisador deve, portanto, retornar à análise inter-participantes para verificar se isso está acontecendo. As análises inter e intra-participantes podem se suceder, em um processo iterativo, até que o material coletado seja apreendido em toda a sua complexidade.

\section{Algumas Breves Considerações sobre Validade $e$ Generalização}

Ao contrário do que muitos imaginam, a preocupação com a validade e a generalização dos resultados não é exclusividade das pesquisas quantitativas. Tal como acontece no já discutido caso do conceito de amostra, os conceitos de validade e generalização são transportados do campo da pesquisa quantitativa para o da pesquisa qualitativa e, neste, têm revistas tanto sua definição quanto as bases para sua aplicação.

A maioria dos pesquisadores que trabalham com métodos qualitativos não crê na existência de uma única verdade nas ciências humanas e sociais (Taylor, 2001b). Assim sendo, esses pesquisadores vêem, como sua, não a tarefa de testar hipóteses, estabelecer leis ou fazer previsões, mas a de oferecer interpretações - sempre parciais e relativas a determinados contextos sociais e históricos - dos complexos fenômenos humanos e sociais que estudam (Taylor, 2001a, 2001b).

Neste novo cenário, o conceito de validade tem que ser revisto. Diferentes pesquisadores, contudo, o revêem de diferentes modos. Na maioria das vezes, validade se torna uma questão de credibilidade. Para alguns, a credibilidade é alcançada se, mediante a comparação dos resultados obtidos com o que acontece no mundo externo, é dada aos fenômenos sob investigação a chance de provar que o pesquisador está errado (Maxwell, 2005). Já outros adotam critérios internos à pesquisa para avaliar sua credibilidade. Weiss (1994), por exemplo, equaciona validade a verdade e aponta duas formas principais de lidar com esta última: (a) investigar a consistência interna do que os entrevistados dizem; e (b) confiar na qualidade das entrevistas. Seidman (1998) e Rubin e Rubin (2005) também usam a consistência interna como critério de validade ou credibilidade. Seidman verifica a consistência do que os entrevistados dizem nas diferentes entrevistas que realiza com cada um deles. Enquanto isso, Rubin e Rubin fazem perguntas do mesmo teor em diferentes pontos da entrevista e examinam a consistência das respostas dadas às mesmas.

O MEDS, em contrapartida, não se preocupa com a verdade ou com a consistência interna, mas sim com a sinceridade dos depoimentos que coleta. Não concebe as contradições intencionalmente provocadas por seus roteiros como indicativas de que os entrevistados não estão dizendo a verdade. Concebe-as como um importante testemunho da espontaneidade e sinceridade de suas respostas (pois é humano não gostar de ser pego em contradição). Dado que trabalha com amostras homogêneas que são expostas a um mesmo roteiro, também adota a recorrência das respostas dadas pelos diferentes participantes como critério de credibilidade (na medida em que é altamente improvável que muitos sejam insinceros do mesmo modo).

Uma outra revisão do conceito de validade é feita por Turato (2003). Como, na pesquisa qualitativa, os procedimentos de validação e generalização estão muito próximos, ele considera validado um resultado quando este atende a um critério que outros autores adotam para avaliar seu potencial de generalização: o da identificação do leitor com os resultados da pesquisa apresentada. 
De fato, Rubin e Rubin (2005) e Seidman (1998) argumentam que os resultados de uma amostra pequena, mesmo quando intencional e heterogênea, podem ser generalizados porque sua profundidade permite que os leitores com eles se identifiquem. Turato (2003) chega a afirmar que o leitor é um agente generalizante de conceitos e pressupostos finais. Já Maxwell (2005) salienta a importância de citações detalhadas e ricas do material coletado com as quais os leitores podem se identificar.

Maxwell (2005), Taylor (2001b) e Weiss (1994) apresentam vários argumentos que fundamentam a generalização de pequenas amostras intencionais. Entre eles estão o de que, por trás das diferenças pessoais, existe uma estrutura universal que pode ser alcançada pela entrevista em profundidade (Weiss) e o de que recorrências são indicativas de conhecimento social partilhado ou de idéias e crenças culturalmente difundidas (Taylor, 2001b). O que chama mais atenção nessas discussões é que, contrariamente ao que poderia ser esperado, nenhum desses autores duvida que seja possivel generalizar a partir de amostras pequenas e nãorandômicas.

O MEDS também adota a posição de que é possível fazer generalizações a partir de amostras intencionais de pequeno porte. As bases que usa para essas generalizações são, porém, diferentes e mais exigentes. De acordo com o MEDS, os aspectos recorrentes identificados a partir de amostras homogêneas - principalmente quando é usado um perfil de alta definição - podem ser generalizados para os membros da população mais ampla, unicamente quando estes exibem as mesmas características que serviram de base para o recrutamento dos participantes da pesquisa. Também segundo o MEDS, por conta da já mencionada proximidade dos procedimentos de validação e generalização, o leitor que se identifica com os resultados da pesquisa simultaneamente dá credibilidade aos dados coletados e atesta o poder de generalização dos resultados.

\section{Aspectos Positivos de uma Revolução Ainda em Curso}

Basta verificarmos o número de títulos que serão lançados em futuro próximo somente pela editora anglo-saxã Sage, (www.sagepub.com), que se especializou em publicações sobre pesquisa qualitativa, para compreendermos que a revolução qualitativa continua em pleno curso nas ciências sociais e humanas.

As novas propostas metodológicas a serem divulgadas em futuro próximo vão se somar àquelas inúmeras já existentes, gerando um campo de opções ainda mais vasto. Entre as metodologias que formam esse campo (das quais foram examinadas apenas algumas) continuarão existindo muitas divergências (como aquelas que discutimos ao longo deste trabalho), mas muito provavelmente uma coisa continuará inalterada: a firme convicção de que os métodos qualitativos são especialmente adequados para a apreensão da complexidade dos fenômenos humanos e sociais, principalmente em tempos de mudança.

Diferentemente do que muitos podem pensar, a progres- siva ampliação do campo da pesquisa qualitativa nada tem de negativo. Pelo contrário, todos têm a ganhar com a fecundação mútua dos métodos que compõem esse campo e com o constante refinamento metodológico que as tensões entre eles tornam necessário. São exatamente esse refinamento e essa fecundação que viabilizarão métodos cada vez mais sensíveis que, por sua vez, produzirão um conhecimento progressivamente mais aprofundado dos complexos fenômenos sociais e humanos.

\section{Referências}

Berger, P. L., \& Luckmann, E. (1967). The social construction of reality. New York: Anchor.

Bernstein, B. (1977). Class, codes and control: Vol. 3. London: Routledge \& Kegan Paul.

Biasoli-Alves, Z. M. (1998). A pesquisa psicológica: Análise de métodos e estratégias na construção de um conhecimento que se pretende científico. In G. Romanelli \& Z. M. Biasoli-Alves (Eds.), Diálogos metodológicos sobre pesquisa (pp. 135-157). Ribeirão Preto, SP: Legis Summa.

Brockmeier, J., \& Harré, R. (2003). Narrativa: Problemas e promessas de um paradigma alternativo. Psicologia: Reflexão e Crítica, $16(3)$, 525-535.

Chizotti, A. (2000). Pesquisa em ciências humanas e sociais (4. ed.). São Paulo, SP: Cortez.

Denzin, N. K., \& Lincoln, Y. S. (Eds.). (2000a). Handbook of qualitative research (2nd ed.). Thousand Oaks, UK: Sage.

Denzin, N. K., \& Lincoln, Y. S. (2000b). Introduction: the discipline and practice of qualitative research. In N. K. Denzin \& Y. S. Lincoln (Eds.), Handbook of qualitative research (2nd. ed., pp. 1-28). Thousand Oaks, UK: Sage.

Denzin, N. K., \& Lincoln, Y. S. (2000c). Preface. In N. K. Denzin \& Y. S. Lincoln (Eds.), Handbook of qualitative research (2nd ed., pp. ix $-\mathrm{xx}$ ). Thousand Oaks, UK: Sage.

Foucault, M. (1966). Les mots et les choses. Paris: Gallimard.

Gomes, W. (1997). A entrevista fenomenológica e o estudo da experiência consciente. Psicologia USP, 8(2), 305-336.

Jodelet, D. (2003). Aperçus sur les methodologies qualitatives. In S. Moscovici \& F. Buschini (Eds.), Les méthodes des sciences humaines (pp. 139-161). Paris: PUF

Kvale, S. (1996). Interviews: An introduction to qualitative research. Thousand Oaks, UK: Sage.

Labov, W. (1972). Language in the inner city. Philadelphia, PA: University of Pennsylvania Press.

Lincoln, Y. S., \& Guba, E. G. (2000). Paradigmatic controversies, contradictions and emerging confluences. In N. K. Denzin \& Y. S. Lincoln (Eds.), Handbook of qualitative research (2nd ed., pp. 163-188). Thousand Oaks, UK: Sage.

Martins, H. H. T. S. (2004). Metodologia qualitativa de pesquisa. Educação e Pesquisa, 30(2), 289-300.

Maxwell, J. A. (2005). Qualitative research design: An interactive approach (2nd ed.). Thousand Oaks, UK: Sage.

Nicolaci-da-Costa, A. M. (1987). Sujeito e cotidiano: Um estudo da dimensão psicológica do social. Rio de Janeiro, RJ: Campus.

Nicolaci-da-Costa A. M. (1994). A análise de discurso em questão. Psicologia: Teoria e Pesquisa, 1O(2) 317 - 331.

Nicolaci-da-Costa, A. M. (1998). Na malha da Rede: Os impactos intimos da Internet. Rio de Janeiro, RJ: Campus.

Nicolaci-da-Costa, A. M. (2004). Impactos psicológicos do uso de celulares: Uma pesquisa exploratória com jovens brasileiros. Psicologia: Teoria e Pesquisa, 20(2), 165-174. 
Nicolaci-da-Costa, A. M. (2007). O Campo da Pesquisa Qualitativa e o Método de Explicitação do Discurso Subjacente (MEDS).

Rubin, H. J., \& Rubin, I. S. (2005). Qualitative interviewing: The art of hearing data (2nd ed.). Thousand Oaks, UK: Sage.

Sapir, E. (1949). Language. New York: Harcourt Brace Jovanovich.

Sauret, M.-J. (2003). A pesquisa clínica em Psicanálise. Psicologia USP, 14(3), 89-104.

Saussure, F. de (1974). Course in general linguistics. Bungay, UK: Fontana. (Original publicado em 1916)

Seidman, I. (1998). Interviewing as qualitative research: A guide for researchers in education and the social sciences(2nd ed.). New York: Teachers College Press.

Taylor, S. (2001a). Evaluating and applying discourse analytic research. In M. Wetherell, S. Taylor \& S. J. Yates (Eds.), Discourse as data: A guide for analysis (pp. 311-330). London: Sage.
Taylor, S. (2001b). Locating and conducting discourse analytic research. In M. Wetherell, S. Taylor \& S. J. Yates (Eds.), Discourse as data: A guide for analysis (pp. 5-48). London: Sage.

Turato, E. R. (2003). Tratado da metodologia da pesquisa clínicoqualitativa. Petrópolis, RJ: Vozes.

Weiss, R. S. (1994). Learning from strangers: The art and method of qualitative interview studies. New York: Free Press.

Wengraf, T. (2004). Qualitative research interviewing: Semistructured, biographical and narrative methods. London: Sage.

Wetherell, M., Taylor, S., \& Yates, S. J. (Eds.). (2001). Discourse as data: A guide for analysis. London: Sage.

Recebido: $21 / 10 / 2005$

$1^{a}$ revisão: $19 / 04 / 2006$

Aceite final: 21/06/2006 